Article

\title{
Antinociceptive Activity and Toxicity Evaluation of the Fatty Oil from Plukenetia polyadenia Mull. Arg. (Euphorbiaceae)
}

Amanda S. Mota ${ }^{1}$, Anderson B. de Lima ${ }^{1,2}$, Thayana Lucy F. Albuquerque ${ }^{1}$, Tiago S. Silveira ${ }^{2}$, José Luiz M. do Nascimento ${ }^{3}$, Joyce Kelly R. da Silva ${ }^{2, *}$, Alcy F. Ribeiro ${ }^{4}$, José Guilherme S. Maia ${ }^{5,6, *}$ and Gilmara N. T. Bastos ${ }^{1, *}$

1 Laboratório de Neuroinflamação, Universidade Federal do Pará (UFPA), 66075-900 Belém, PA, Brazil; E-Mails: amanda.sodre.mota@gmail.com (A.S.M.); andersonbentes@uol.com.br (A.B.L.); thayanalucy@gmail.com (T.L.F.A.)

2 Programa de Pós-Graduação em Biotecnologia, Universidade Federal do Pará (UFPA), 66075-900 Belém, PA, Brazil; E-Mail: silveira.t@gmail.com

3 Laboratório de Neuroquímica Molecular e Celular, Universidade Federal do Pará (UFPA), 66075-900 Belém, PA, Brazil; E-Mail: jlmn@ufpa.br

4 Instituto de Ciências Exatas e Naturais, Universidade Federal do Sul e Sudeste do Pará (UNIFESSPA), 68507-590 Marabá, PA, Brazil; E-Mail: favacho@ufpa.br

5 Programa de Pós-Graduação em Química, Universidade Federal do Pará (UFPA), 66075-900 Belém, PA, Brazil

6 Programa de Pós-Graduação em Recursos Naturais, Universidade Federal do Oeste do Pará (UFOPA), 68035-110 Santarém, PA, Brazil

* Authors to whom correspondence should be addressed; E-Mail: joycekellys@ufpa.br (J.K.R.S.); bastosgnt@gmail.com (G.N.T.B.); gmaia@ufpa.br (J.G.S.M);

Tel./Fax: +55-91-3201-7545 (J.K.R.S. \& G.N.T.B. \& J.G.S.M.).

Academic Editor: Isabel C. F. R. Ferreira

Received: 20 December 2014 / Accepted: 3 April 2015 / Published: 30 April 2015

\begin{abstract}
Seed oil (Pp-oil) of Plukenetia polyadenia is used by native people of the Brazilian Amazon against arthritis and rheumatism, spreading it on the arms and legs to reduce the pain and inflammation. Pp-oil was obtained by pressing dried seeds at room temperature to give a $47.0 \%$ yield of oil. It was then subjected to fatty acid composition analysis. The principal fatty acids were linoleic acid (46.5\%), $\alpha$-linolenic acid (34.4\%) and oleic acid (13.9\%). Then, it was evaluated for its antinociceptive activity in mice, using the acetic acid-induced abdominal writhing, hot plate and formalin test models. Additionally,
\end{abstract}


its toxicity was determined. The Pp-oil proved to have no toxicological effects, showing dose-dependent antinociceptive effect under chemical stimulation. At oral doses of $25-100 \mathrm{mg} / \mathrm{kg}$, Pp-oil significantly reduced the abdominal writhes in the writhing test. A higher oral dose of $200 \mathrm{mg} / \mathrm{kg}$ did not induce alterations in the latency time of the hot plate test when compared to the control, suggesting an analgesic activity of peripheral origin. At oral doses of 50 and $100 \mathrm{mg} / \mathrm{kg}$, the Pp-oil significantly reduced the second phase of the algic stimulus in the formalin test. In addition, the antinociception of Pp-oil was reversed by naloxone in the evaluation of its mechanism of action. Therefore, the Pp-oil proved to be safe at very high doses and to show significant analgesic properties. The role of Pp-oil is still being investigated with respect the mechanism of action, but the results suggest that opiod receptors could be involved in the antinociception action observed for the oil of P. polyadenia.

Keywords: Plukenetia polyadenia; Euphorbiaceae; fatty oil; linoleic and $\alpha$-linolenic acids; antinociception activity; toxicity

\section{Introduction}

Plukenetia L. is a neotropical genus of nineteen species belonging to the Euphorbiaceae. Plukenetia polyadenia Müll. Arg. [syn. Elaeophora polyadenia (Müll. Arg.) Ducke, Elaeophora abutaefolia Ducke and Plukenetia abutaefolia (Ducke) Pax \& K. Hoffm.] [1] is a liana that climbs the canopy of tall trees, known as "compadre-de-azeite". It grows in the wet lowland forests and is widespread in the the Amazon basins of the Guyanas, Venezuela, Ecuador, Peru, Bolivia and Brazil [2].

Some of the most common manifestations of diseases that affect millions of people worldwide are pain and inflammation. The dependence of the Amazon rural population with respect to medicinal plants is cultural, and the traditional medicine practitioners have used plants for their health care, particularly in the riparian communities. In Brazil, along the Amazon River and its tributaries, the seed oil of P. polyadenia (Pp-oil) is used by native people against arthritis and rheumatism. It is spread on the arms and legs to reduce the pain and inflammation. A single study of the seeds of $P$. polyadenia was previously reported, with the determination of its fatty acids composition and a preliminary toxicological evaluation [3].

Fatty acids are the primary precursors of important lipid mediators during the inflammatory process, such as arachidonic acid, prostaglandins, thromboxanes, and leukotrienes. Long chain n-3polyunsaturated fatty acids have been investigated for use in the treatment of inflammatory diseases such as rheumatoid arthritis, psoriasis, and ulcerative colitis, because of the presumed anti-inflammatory effects of these fatty acids $[4,5]$. The anti-inflammatory effects of long chain n-3 polyunsaturated fatty acids have been formerly attributed to changes in the production of prostaglandins and leukotrienes, although other studies have emphasized the reduced production of cytokines, as a possible mechanism [6].

The aim of this study was to analyze the fatty acids composition of Pp-oil and evaluate their antinociceptive activity and toxicity, based on its traditional use by the Amazon native population to reduce pain and inflammation in arthritis and rheumatism. 


\section{Results and Discussion}

\subsection{Oil-Composition}

The percentage of the oil of $P$. polyadenia obtained by pressing the dried seeds at room temperature was $36.2 \%$. This rate increases to $47.0 \%$, considering the moisture content retained in the seeds, which was $30 \%$. The extraction with Soxhlet showed a value of $56.2 \%$, when used the $n$-hexane as solvent. Only the pressed dried seed oil was utilized in the experiments. The methylated fatty acids of Pp-oil were identified by GC/FID and GC-MS and are listed in Table 1. In addition, the Pp-oil was analyzed by ${ }^{1} \mathrm{H}-\mathrm{NMR}$, and the assignments of their proton signals match well with the signals of the same methylated fatty acids already described in the literature $[7,8]$.

Table 1. Methylated fatty acids of the oil of Plukenetia polyadenia.

\begin{tabular}{ccccc}
\hline Constituents & RI $_{\text {Calc }}$ & RI $_{\text {Lit }}$ & Oil \% & Identification \\
\hline Palmitic acid, methyl ester & 1925 & 1921 & 2.9 & GC, MS \\
Linoleic acid, methyl ester & 2097 & 2092 & 46.5 & GC, MS \\
$\alpha$-Linolenic acid, methyl ester & 2104 & 2098 & 34.4 & GC, MS \\
Oleic acid, methyl ester & 2112 & 2107 & 13.9 & GC, MS \\
Stearic acid, methyl ester & 2129 & 2124 & 1.5 & GC, MS \\
Arachidonic acid, methyl ester & 2279 & 2274 & 0.8 & GC, MS \\
\hline Total & & & 100.0 & GC, MS \\
\hline
\end{tabular}

$\mathrm{RI}_{\text {Calc }}=$ Retention index on DB-5 capillary column using $n$-alkanes (C8-C30) as standards; $\mathrm{RI}_{\mathrm{Lit}}=$ Retention; index on similar capillary column described in the literature $[9,10]$; $\mathrm{GC}=$ Gas chromatography analysis: co-elution with methylated fatty acid standards; MS = Mass spectra.

\subsection{Acute Toxicity (LD50)}

Pp-oil did not demonstrate any behavior changes or mortality in mice at doses of $2000 \mathrm{mg} / \mathrm{kg}$ and $5000 \mathrm{mg} / \mathrm{kg}$, during the three days of the experiment.

\subsection{Clinical Chemistry and Histophatology}

The results of total cholesterol (CHO), low-density lipoprotein (LDL), high-density lipoprotein (HDL) and triglycerides (TG) of rats subjected to the experiment, using Pp-oil at doses of $100 \mathrm{mg} / \mathrm{kg} / \mathrm{day}$ and $200 \mathrm{mg} / \mathrm{kg} /$ day, are shown in Figure 1. Values are shown as mean \pm S.E.M (s.e.m.) and did not indicate chemical alterations in mice, when compared to the control. The histopathological examination can be seen in Figures 2 and $3 \mathrm{~A}-\mathrm{C}$, and also did not present any alteration in the morphology of the organs, at the used doses, when compared to the control. 


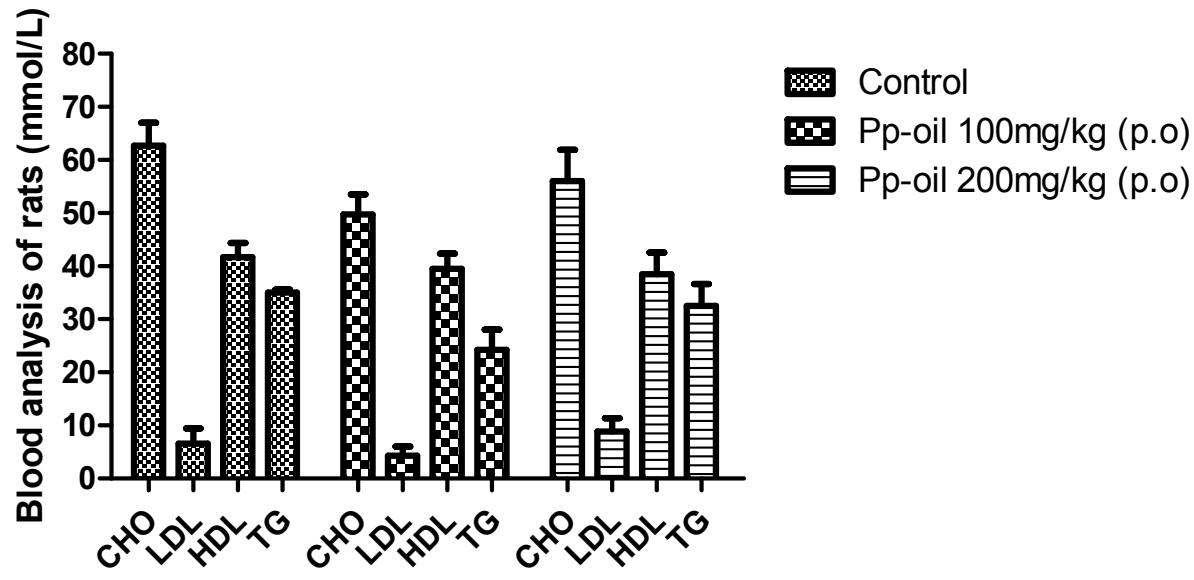

Figure 1. Clinical chemistry results for oral doses of $100 \mathrm{mg} / \mathrm{kg}$ and $200 \mathrm{mg} / \mathrm{kg}$ compared with control. Values are mean \pm S.E.M (s.e.m.) and abbreviations: CHO, total cholesterol; LDL, low-density lipoprotein; HDL, high-density lipoprotein; TG, triglycerides.
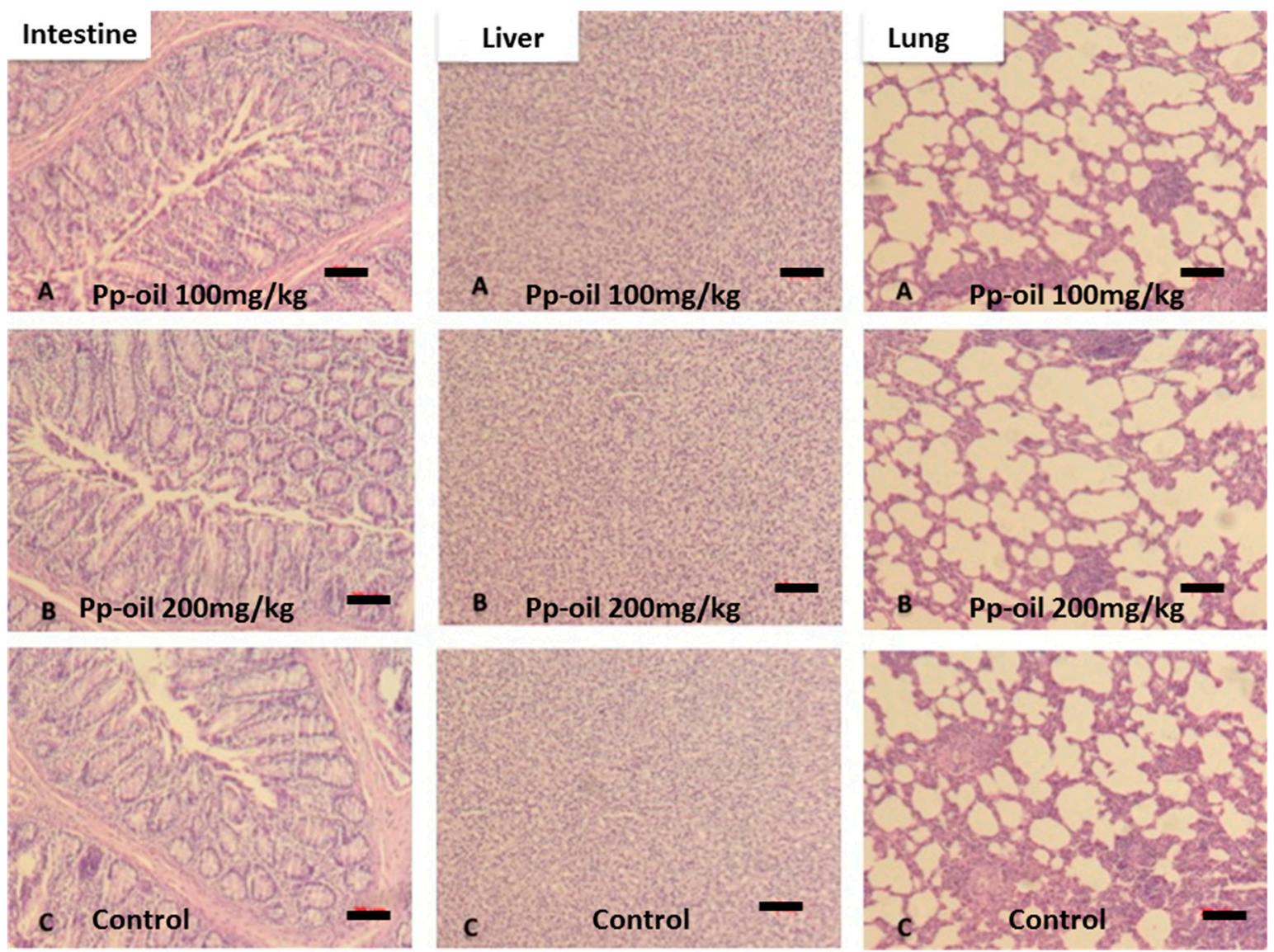

Figure 2. Histopathology of intestine, liver and lung: (A) $100 \mathrm{mg} / \mathrm{kg}$; (B) $200 \mathrm{mg} / \mathrm{kg}$ and (C) control. Dark bar: $20 \mu \mathrm{m}$. 


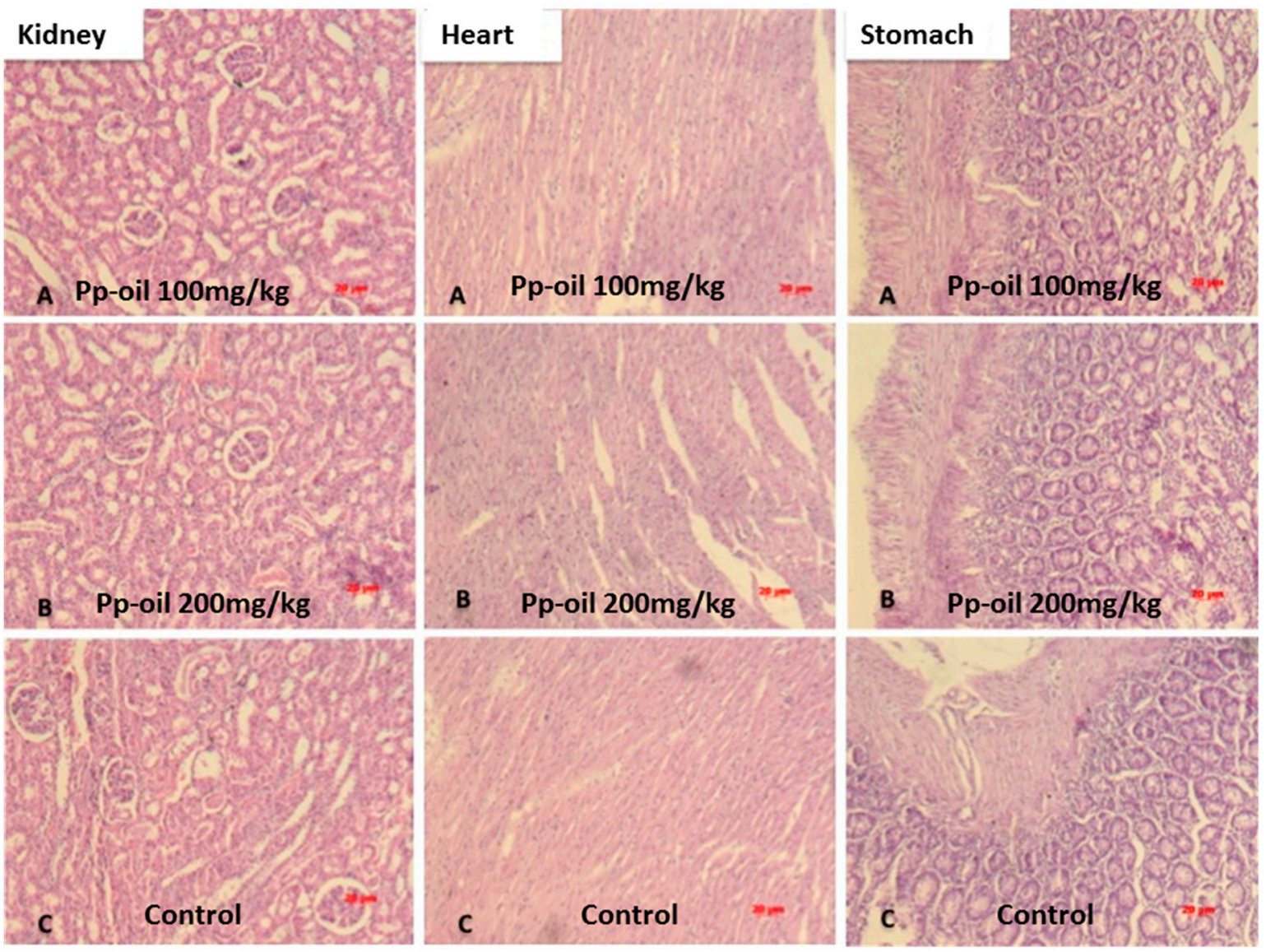

Figure 3. Histopathology of kidney, heart and stomach: (A) $100 \mathrm{mg} / \mathrm{kg}$; (B) $200 \mathrm{mg} / \mathrm{kg}$ and (C) control. Dark bar: $20 \mu \mathrm{m}$.

\subsection{Acetic Acid-Induced Writhing}

Oral administration of the Pp-oil $(25,50$ and $100 \mathrm{mg} / \mathrm{kg})$ significantly decreased the number of writhes in mice induced by acetic acid, in comparison to the animals that received only the vehicle (Figure 4). These effects were dose-dependent.

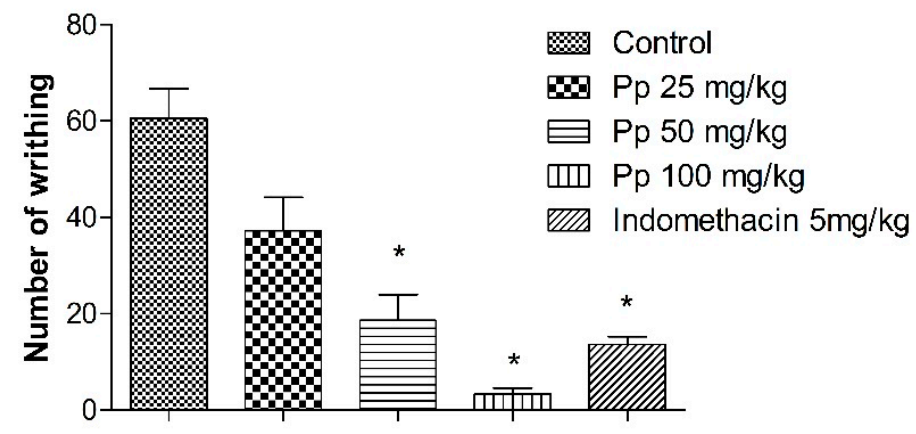

Figure 4. Effect of oral doses of Pp-oil on the nociception induced by intraperitoneal injection of acetic acid. Mean \pm s.e.m., * Significantly different from the control $(p<0.05$, $\mathrm{F}=22.59$, ANOVA, Student-Newman-Keuls $t$-test) at given a time. 


\subsection{Hot Plate Test}

Administration of Pp-oil dosed at $200 \mathrm{mg} / \mathrm{kg}$ did not induce alterations in the latency time in mice, when compared to the control (Figure 5).

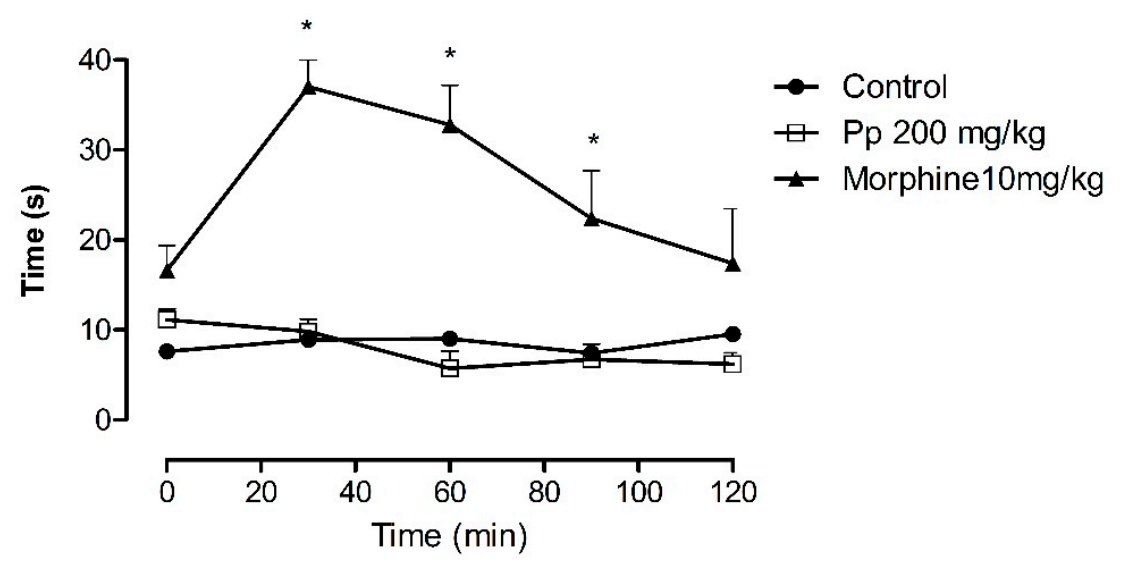

Figure 5. Hot plate test. Time-course of the effects of Pp-oil on thermal nociception. Abscissa time (min) after Pp-oil (oral), morphine (s.c.). Ordinate latency time (s) for the response to thermal stimulation $\left(55 \pm 0.5^{\circ} \mathrm{C}\right.$, Mean \pm s.e.m., $\left.n=5\right)$ for each Pp-oil dose. * significantly different from the control $(p<0.05, \mathrm{~F}=15.96$; ANOVA, Dunnett's $t$-test) at given a time.

\subsection{Formalin Test}

The Pp-oil (50 and $100 \mathrm{mg} / \mathrm{kg}$ ) injected in mice $60 \mathrm{~min}$ before formalin showed a significant antinociception effect, reducing the liking time in the second phase (inflammatory) in a dose-dependent manner (Figure 6).
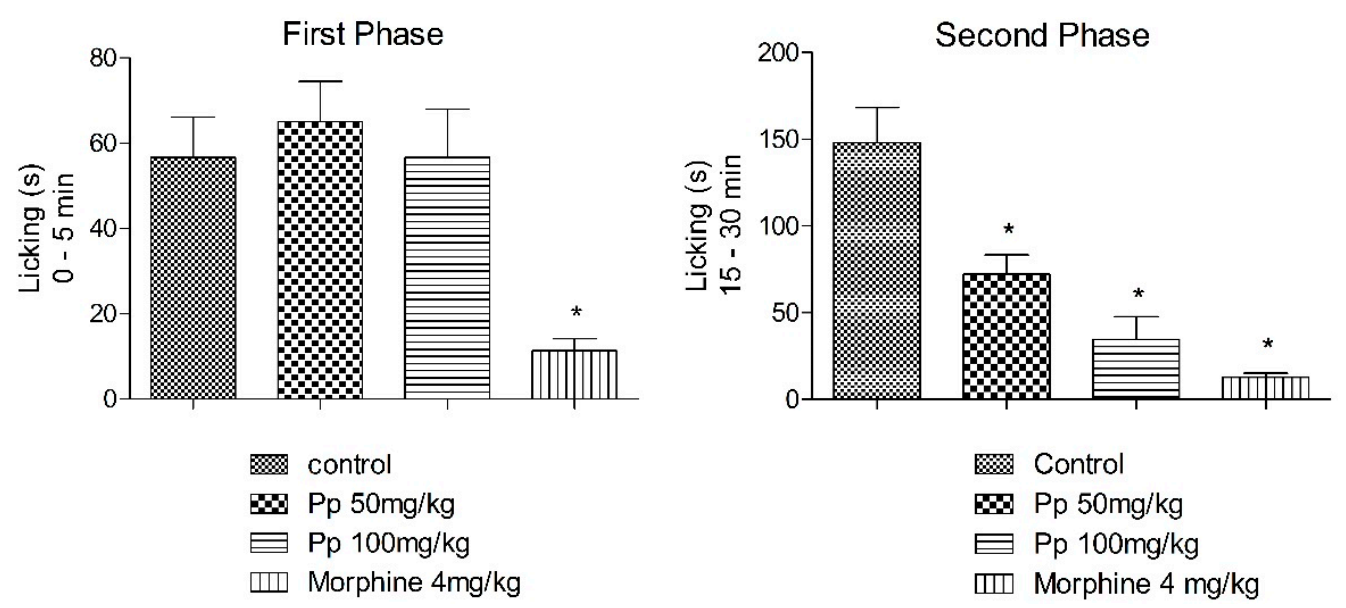

Figure 6. Formalin test: Phase 1 and Phase 2. Each group represents mean \pm s.e.m. of 5 animals. $* p<0.05$ when compared to the control value, $\mathrm{F}=29.04$ (ANOVA, Student-Newman Kuels' test). 


\subsection{Mechanism of Action}

The pre-treatment of animals with naloxone showed a significant effect on the antinociception, during the writhing test. Naloxone reversed the effect caused by morphine and Pp-oil (Figure 7).

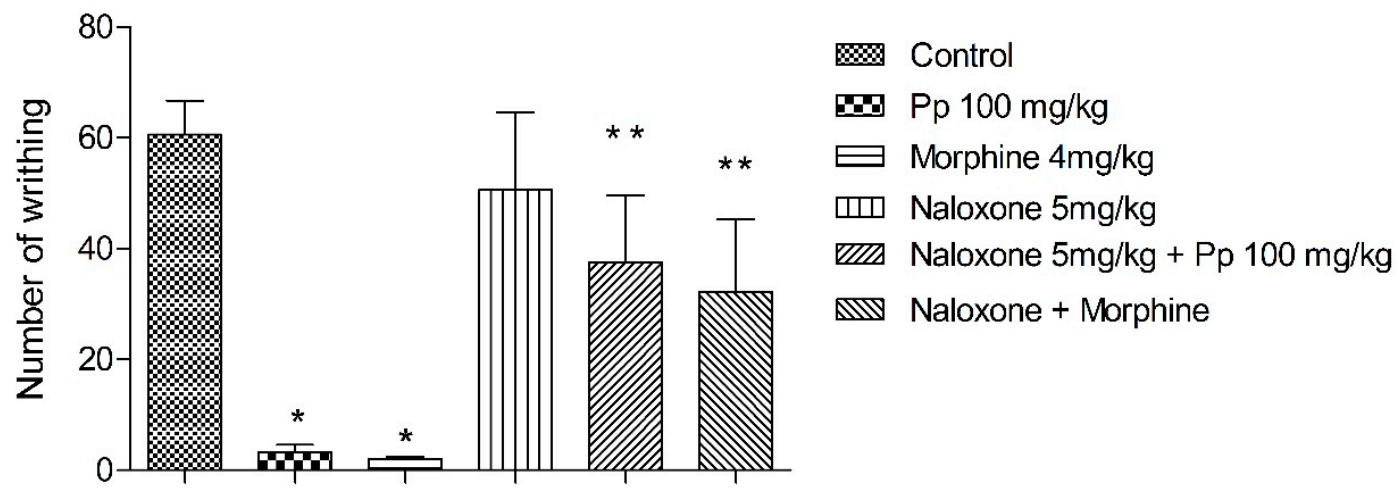

Figure 7. Mechanism of action. Each group represents mean \pm s.e.m. of 5 animals. $* p<0.05$ when compared to control value; $* * p<0.05$ when compared to agonist plus antagonists $v s$. agonist alone, $\mathrm{F}=4.855$.

\subsection{Discussion}

The percentages of linoleic acid (LA, 18:2 n-6, omega-6, 46.5\%) and $\alpha$-linolenic acid ( $\alpha$-LNA, 18:3 $\mathrm{n}-3$, omega-3, 34.4\%) in Pp-oil were significant, in comparison to other fatty oils produced in the Brazilian Amazon region. Oleic acid (OA, 18:1 n-9, omega 9, 13.9\%) was also present in the oil but with a lower content. Some oils from the Euphorbiaceae, such as Ricinus communis L. and Jatropha curcas L., contains triglycerides composed of fatty acids considered laxative and toxic [11,12]. It is not the case of Pp-oil, which is edible and composed only of fatty acids commonly found in vegetable oils used for cooking. Therefore, it was presumed that the administration of large quantities of PP-oil in mice would not elicit any toxic effects or death. This was confirmed by LD50, values.

The possibility of health benefits associated with the association of an omega-3 diet (polyunsaturated fatty acids, $\omega-3$ PUFAs) have been described for several chronic conditions, including cardiovascular, neurodegenerative and neoplastic diseases [13]. Ample evidence has emerged over the last few years to show the critical role played by inflammation in the pathogenesis of these illnesses. Previously, they were not related to inflammation. Recently has been hypothesized that the effects of $\omega-3$ PUFAs may be linked to their direct anti-inflammatory activity, as well its metabolites, eicosapentaenoic acid (EPA, 20:5) and docosahexaenoic acid (DHA, 22:6) [13]. n-6 PUFAs belong to another important family of PUFAs, also used in dietary and mainly concentrated in vegetable oils. Among the components of these two classes of PUFAs (n-3 and n-6), $\alpha$-linolenic acid ( $\alpha$-LNA, 18:3 n-3) and linoleic acid (LA, 18:2 n-6) are considered essential for the human diet. The mammalian cells do not possess the desaturases able to place the double bonds specifically in n-3 and n- 6 positions on the fatty acid carbon chain, differently from vegetable cells, along the synthetic pathway. Various synthesis steps produce n-6 PUFA arachidonic acid (AA, 20:4 n-6). It is highly represented in the membranes 
and is a precursor of the eicosanoids, the bioactive compounds that mediate the inflammatory process, as prostaglandins, thromboxanes, and leukotrienes.

The acute toxicity study was considerate as the initial phase of further sub-chronic studies. Doses up to $5000 \mathrm{mg} / \mathrm{kg}$ did not exhibit any mortality or any signs of toxicity after oral administration. This treatment may thus be considered as no-observed-adverse-effect level (NOAEL) [14]. The oral LD50 value in mice, when higher than $5000 \mathrm{mg} / \mathrm{kg}$ is described as class five (nontoxic substances) of the globally harmonized classified system for chemical substances and mixtures [15].

$\mathrm{Pp}$-oil produced antinociception effects in the studied nociception models. The acetic acid-induced writhing reaction in mice has been primarily used as a screening tool for the assessment of analgesic or anti-inflammatory properties of new agents and is described as a typical model for visceral inflammatory pain [16]. The local irritation provoked by a test agent in the intraperitoneal cavity triggers a variety of mediators, such as bradykinin, substance P and the prostaglandins, especially, prostacyclin (PGI2), as well as some cytokines such as Interleukin-1 beta (IL-1 $\beta$ ), tumor necrosis factor alpha (TNF- $\alpha$ ), and Interleukin 8 (IL-8) [17-19]. These mediators can activate chemo-sensitive nociceptors that contribute to the onset of inflammatory pain. Pp-oil was able to reduce the writhing at doses of 25 and $50 \mathrm{mg} / \mathrm{kg}$, suggesting that its antinociception effect could be related to inhibition of the release of mediators in response to acetic acid. The fatty oil could be inhibiting the production of a range of inflammatory proteins, including cyclooxygenase-2 (COX-2), inducible nitric oxide (NO) synthase, TNF- $\alpha$, IL-1, IL-6, IL-8, and IL-12 in cultured endothelial cells, monocytes, macrophages, and dendritic cells. These inhibitory effects of long-chain n-3polyunsaturated fatty acids (PUFAs) seem to involve the decrease of IkB phosphorylation and reduce the activation of NFkB. These effects are associated with a reduction in the activation of the signaling proteins such as mitogen-activated protein kinases [20,21].

The hot plate test is a particular central antinociception test in which opioid agents exert their analgesic effects via supraspinal and spinal receptors. It is useful for the evaluation of centrally acting analgesics that are known to elevate the pain threshold of mice towards heat [22,23]. The Pp-oil did not alter the increase in latency for jumping or licking. These results are suggestive of an antinociception action of Pp-oil via a peripheral mechanism rather than a central acting mechanism.

The formalin test is believed to resemble clinical pain more closely in comparison with other tests that employ mechanical or thermal stimuli $[16,24]$. This test is a model of nociceptive response in two distinct phases, involving different mechanisms. The first phase (neurogenic pain) results from the direct chemical stimulation of myelinated and unmyelinated nociceptive afferent fibers, mainly $\mathrm{C}$ fibers, which can be suppressed by opioid analgesic drugs like morphine [25,26]. In the second phase, inflammatory mediators in the peripheral tissues, such as prostaglandins, serotonin, histamine and bradykinin, induce functional changes in the neurons, of the spinal dorsal horn that, in the long term, promote facilitation of synaptic transmission at the spinal level [27-29]. In this model, Pp-oil inhibited the licking response of mice in the second phase (Figure 4), suggesting this compound exerts its antinociception effects connected with peripheral mechanisms. The $\alpha$-linolenic acid and the linoleic acid are known also as inhibitors of COX-1 and COX-2 [30,31], as well the morphine can promote a peripheral analgesia [32]. To this respect, naloxone, an opioid antagonist, was tested in the acetic acid writhing. It showed an influence on the antinociception action of Pp-oil (100 mg/kg, p.o.). This fact 
suggests the participation of the opioid system in the modulation of pain provoked by administration of Pp-oil.

The results of clinical chemistry and histopathology showed no significant difference between the two doses used and the control. Tissues were evaluated for the presence or absence of polymorphonuclear and mononuclear leukocyte; edema; apoptotic bodies and necrotic damage (see Figures 2 and 3 ).

\section{Experimental Section}

\subsection{Drugs and Chemicals}

The following drugs and chemicals were used: morphine (Laboratório Cristália, Itapira, SP, Brazil), indomethacin, sodium methoxide, boron trifluoride, $n$-alkanes (Sigma, St. Louis, MO, USA), naloxone (Laboratório Cristália), acetic acid, formalin, hexane, diethyl ether, methanol (Vetec, Duque de Caxias, RJ, Brazil).

\subsection{Animals}

Swiss male mice (20-25 g) were obtained from the Instituto Evandro Chagas (Belém, Pará, Brazil). They were randomly assigned to groups of ten animals and maintained in plastic boxes, with food and water ad libitum, under light and dark cycle (12 h, each). The room temperature was maintained at $22 \pm 1{ }^{\circ} \mathrm{C}$. The animals were acclimatized to the laboratory for at least $1 \mathrm{~h}$ before the experiments that were carried out between $8 \mathrm{~h}$ and $13 \mathrm{~h}$ in order to avoid circadian influence. All experiments reported in this study were conducted in accordance with current guidelines for the care of laboratory animals and ethical guidelines for investigation of experimental pain in conscious animals (CEPAE-UFPA 124-13). All efforts were made to minimize the number of animals used and their suffering.

\subsection{Plant Material}

The fruits of P. polyadenia were collected in a lowland area near of the Guamá River, and the municipality of Santa Isabel do Pará, Pará, Brazil, during the rainy season, April 2011. The plant was identified and deposited (MG 170411) in the Herbarium of Emílio Goeldi Museum, Belém, Pará, Brazil. The four seeds of the fruit were separated, dried at room temperature, then grinded and submitted to the oil extraction using an Expeller type press and a Soxhlet extractor. The moisture content of the seeds was calculated by drying in an electric oven until constant weight. The oil extracted from the pressed dried seeds was coded as Pp-oil and utilized in the experiments.

\subsection{Fatty Acids Esterification}

The Pp-oil $(100 \mathrm{mg})$ was placed in a test tube $(20 \mathrm{~cm})$ with stopper. A methanol solution $(3 \mathrm{~mL}) \mathrm{of}$ sodium methoxide (3\%) was added. The mixture was heated in a water bath at boiling temperature for $3 \mathrm{~min}$. After, a methanol solution $(3 \mathrm{~mL})$ of boron trifluoride $(10 \%)$ was added. The mixture was again heated in a water bath for other $3 \mathrm{~min}$. The mixture was extracted with hexane $(1 \mathrm{~mL})$ and diethyl ether 
$(2 \mathrm{~mL})$ in a volumetric flask $(50 \mathrm{~mL})$ containing distilled water. The organic layer was separated to a vial $(5 \mathrm{~mL})$, and the solvent evaporated. The Pp-oil esterification was done in duplicate $[33,34]$.

\subsection{Oil-Composition Analysis}

The Pp-oil was analyzed in a THERMO DSQ II GC-MS instrument, under the following conditions: DB-5ms (30 $\mathrm{m} \times 0.25 \mathrm{~mm} ; 0.25 \mathrm{~mm}$ film thickness) fused-silica capillary column; programmed temperature: $60-240{ }^{\circ} \mathrm{C}\left(3{ }^{\circ} \mathrm{C} / \mathrm{min}\right)$; injector temperature: $250{ }^{\circ} \mathrm{C}$; carrier gas: helium, adjusted to a linear velocity of $32 \mathrm{~cm} / \mathrm{s}$ (measured at $100{ }^{\circ} \mathrm{C}$ ); injection type: splitless ( $2 \mathrm{~mL}$ of a 1:1000 hexane solution); split flow was adjusted to yield a 20:1 ratio; septum sweep was a constant $10 \mathrm{~mL} / \mathrm{min}$; EIMS: electron energy, $70 \mathrm{eV}$; temperature of ion source and connection parts: $200{ }^{\circ} \mathrm{C}$. The quantitative data regarding the methylated fatty acids were obtained by peak area normalization using a FOCUS GC/FID operated under similar conditions of the GC-MS, except for the carrier gas, which was nitrogen. The retention index was calculated for all the constituents using a homologous series of $n$-alkanes $\left(\mathrm{C}_{8}-\mathrm{C}_{30}\right.$, Sigma-Aldrich, St. Louis, MO, USA). Individual components were identified by comparison of both mass spectrum and GC retention data with authentic compounds which were previously analyzed and stored in a private library, as well as with the aid of commercial libraries containing retention indices and mass spectra of methylated fatty acids [9,10]. The standards of methylated fatty acids were purchased from Sigma-Aldrich Brazil.

\subsection{NMR Analysis of Pp-Oil}

The ${ }^{1} \mathrm{H}-\mathrm{NMR}$ spectrum was obtained in a Varian Mercury NMR instrument at $300 \mathrm{MHz}$, using $\mathrm{CDCl}_{3}$ as solvent.

\subsection{Acute Toxicity (LD50)}

Sixty male mice were used, aged $47 \pm 2$ days, body mass index between 20 and $38 \mathrm{~g}$. They were divided into five groups of twelve. Each group fasted for $12 \mathrm{~h}$ received oral doses of Pp-oil between 2000 to $5000 \mathrm{mg} / \mathrm{kg}$ according to the body weight of each animal. Initially, the animals were observed for four $\mathrm{h}$ and placed in cages with food and water ad libitum and, then, kept for an additional $48 \mathrm{~h}$. A separate group of animals was used as a control group, with regular food and water. The experiment aimed to observe the number of deaths in each group relative to the total number of animals treated with the Pp-oil. The toxicological effect was based on mortality, which was expressed as the medium lethal dose $\left(\mathrm{LD}_{50}\right)[35,36]$.

\subsection{0-Day Chronic Oral Toxicity (Experimental Design)}

This study was based on the enhanced OECD test, guideline 407 [37]. Briefly, rats at seven weeks of age were weighed and randomly assigned to four groups, with ten males and ten females in each cluster. Pp-oil was administered to the rats once daily by oral gavages at doses of zero (control), 100 and $200 \mathrm{mg} / \mathrm{kg} /$ day for at least 28 days, at a dosing volume of $5 \mathrm{~mL} / \mathrm{kg}$ body weight. All animals were killed by exsanguinations under pentobarbital anesthesia between study days 31 and 32, and were autopsied. Blood samples for clinical chemistry were obtained from the abdominal aorta prior to necropsy. 


\subsection{Histopathology}

All animals were subject to necropsy. Kidney, heart, stomach, liver, lung and intestine were fixed by immersion in neutral buffered formalin (10\%). The samples were embedded in paraffin wax. Histological sections were stained with hematoxylin and eosin. The tissues were examined using light microscopy.

\subsection{Clinical Tests}

Blood samples for the hematology and biochemistry evaluation were collected from the retro-orbital plexus under light anesthesia induced by $\mathrm{CO}_{2}$ inhalation. EDTA was used as an anticoagulant for the hematology samples in the routine blood test and lithium heparin for the blood biochemistry. Food was held for approximately $18 \mathrm{~h}$ before blood collection. The samples were collected early in the working day to reduce biological variation. The standard biochemistry tests were used to found out metabolism products. Serum biochemistry was performed using a spectrophotometer (Hitachi7180+ISE full automatic biochemical analyzer, Hitachi Ltd., Gaoke, Japan) for the following analyses: total cholesterol (CHO), low-density lipoprotein (LDL), high-density lipoprotein (HDL) and triglycerides (TG).

\subsection{Antinociceptive Activity}

\subsubsection{Acetic Acid-Induced Writhing in Mice}

To evaluate the possible peripheral effects of the Pp-oil as analgesic, the writhing test by acetic acid was performed in mice [38]. Groups of five mice were fasted overnight prior to starting the experiment while given free access to water. The Pp-oil $(25,50$ and $100 \mathrm{mg} / \mathrm{kg})$, indomethacin $(5 \mathrm{mg} / \mathrm{kg})$ or equivalent volumes of vehicle $(0.9 \%$ saline plus $1 \%$ Tween 80$)$ were orally administered in mice $60 \mathrm{~min}$ prior to the acetic acid injection (0.6\%). Indomethacin is a well-known peripheral analgesic drug, and it was used as a positive control. Then, $10 \mathrm{~min}$ after the acetic acid injection, the mice were placed in an observation box, and the writhing number was counted for $30 \mathrm{~min}$.

\subsubsection{Hot Plate Test}

Mice were pre-selected on the hot plate at $55 \pm 0.5{ }^{\circ} \mathrm{C}$. Animals when showing a reaction time (latency for licking the hind feet or jumping) greater than $20 \mathrm{~s}$ were discarded. Then, the selected mice were treated with vehicle (saline), Pp-oil (50, 100 and $200 \mathrm{mg} / \mathrm{kg}$, p.o. via) or morphine (10 mg/kg, s.c.). The reaction time for each mouse was determined on the hot plate, before and after drug administration, at intervals of $30 \mathrm{~min}$. A total period of $45 \mathrm{~s}$ was followed while measuring reaction time [39].

\subsubsection{Formalin Test}

The formalin test was carried out according Hunskaar and Hole (1987) [40]. Formalin (20 $\mu \mathrm{L}, 1 \%)$ was administered to mice via intraplantar route and immediately the licking time was registered for 5 min (first phase, neurogenic). Fifteen minutes after beginning the experiment (second phase, inflammatory), the licking time was recorded for another $15 \mathrm{~min}$. The animals were pre-treated with 
morphine ( $4 \mathrm{mg} / \mathrm{kg}$, s.c.) to assess the possible participation of the opioid system in the antinociception effect, $15 \mathrm{~min}$ before administration of the Pp-oil $(50$ and $100 \mathrm{mg} / \mathrm{kg}$, p.o.) or vehicle $(0.9 \% \mathrm{NaCl}$, $10 \mathrm{~mL} / \mathrm{kg}$, p.o.). The algic responses caused by the first and the second phase of the formalin test were recorded $60 \mathrm{~min}$ after drug and vehicle administration. The other mice group received morphine $30 \mathrm{~min}$ before the formalin injection.

\subsubsection{Evaluation of the Mechanism of Action}

Mice were pre-treated with naloxone ( $5 \mathrm{mg} / \mathrm{kg}$, i.p.) to assess the possible participation of the opioid system in the antinociception effect, $30 \mathrm{~min}$ before the Pp-oil administration (100 mg/kg, p.o.), and morphine ( $4 \mathrm{mg} / \mathrm{kg}$, s.c.) $15 \mathrm{~min}$ before the Pp-oil administration. The nociception response was evaluated by the acetic acid-induced contortions, and the evaluation of the mechanism of action was determined by the reversion of the antinociception effect in the Pp-oil.

\subsection{Statistical Analyses}

Results are expressed as mean \pm S.E.M. Statistical evaluation were made using ANOVA followed by Student-Newman-Keuls or Dunn's test, and the values were considered significantly different when $p<0.05$.

\section{Conclusions}

In summary, at the oral doses tested, Pp-oil can be considered safe as it did not exhibit any lethality or adverse changes in the general behavior in the acute and sub-chronic toxicity studies in mice. It was demonstrated that Pp-oil exhibited dose-related antinociception when assessed in a chemical model, but not in thermal models of nociception in mice. Pp-oil has analgesic activity, which is probably of peripheral origin, according to the tests employed. The mechanisms involved were not yet completely investigated, although it seems that the opioid receptors could be involved in the antinociception action of the Pp-oil.

\section{Acknowledgments}

We are grateful for CNPQ, CAPES and FAPESPA/PA for their financial support.

\section{Author Contributions}

J.L.M.N., J.K.R.S., A.F.R., J.G.S.M., G.N.T.B.: participation in study designed; A.S.M., A.B.L., T.L.F.A., T.S.S., G.N.T.B.: conducting the study in the labs; G.N.T.B., A.S.M., A.B.L., A.F.R., J.K.R.S., J.G.S.M.: Data analyzing and manuscript preparation. All authors read and approved the final manuscript.

\section{Conflicts of Interest}

The authors declare no conflict of interest. 


\section{References}

1. The Plant List. Available online: http://www.theplantlist.org/tpl/record/kew-161498 (accessed on 27 November 2014).

2. Gillespie, L.J.; Armbruster, W.S. A Contribution to the Guianan Flora: Dalechampia, Haematostemon, Omphalea, Pera, Plukenetia and Tragia (Euphorbiaceae) with Notes on Subfamily Acalyphoideae; Smithsonian Institution Press: Washington, DC, USA, 1997.

3. Ribeiro, A.F. Chemical and Toxicological Evaluation of the Fatty Oil from Plukenetia polyadenia Müll. Arg. (Euphorbiaceae). Master's Degree Dissertation, Graduate Program in Chemistry, Universidade Federal do Pará, Belém, PA, Brazil, 15 March 2005.

4. Grimble, R.F.; Tappia, P.S. Modulation of pro-inflammatory cytokine biology by unsaturated fatty acids. Z. Ernahr. 1998, 37, 57-65.

5. O'Shea, M.; Bassaganya-Riera, J.; Mohede, I.C. Immunomodulatory properties of conjugated linoleic acid. Am. J. Clin. Nutr. 2004, 79, 1199-1206.

6. Calder, P.C. Polyunsaturated fatty acids and inflammatory processes: New twists in an old tale. Biochimie 2009, 91, 791-795.

7. Gunstone, F.D.; Shuka, V.K.S. NMR of lipids. Ann. Rep. NMR Spectrosc. 1995, 31, 219-237.

8. Knothe, G.; Kenar, J.A. Determination of the fatty acid profile by ${ }^{1} \mathrm{H}-\mathrm{NMR}$ spectroscopy. Eur. $J$. Lipid Sci. Technol. 2004, 106, 88-96.

9. NIST (National Institute of Standards and Technology). Mass Spectral Library (NIST/EPA/NIH, v. 2.0d); The NIST Mass Spectrometry Data Center: Gaithersburg, MD, USA, 2005.

10. Adams, R.P. Identification of Essencial Oil Components by Gas Chromatography/Mass Spectrometry, 4th ed.; Allured Publishing Corporation: Carol stream, IL, USA, 2007.

11. Ramos, L.C.S.; Tango, J.S.; Savi, A.; Leal, N.R. Variability for oil and fatty acid composition in castor bean varieties. J. Am. Oil Chem. Soc. 1984, 61, 1841-1843.

12. Makkar, H.P.S.; Becker, K.; Sporer F.; Wink, M. Studies on nutritive potential and toxic constituents of different provenances of Jatropha curcas. J. Agric. Food Chem. 1997, 45, 3152-3157.

13. Serini, S.; Fasano, E.; Piccione, E.; Cittadini, A.R.M.; Calviello, G. Dietary n-3 polyunsaturated fatty acids and the paradox of their health benefits and potential harmful effects. Chem. Res. Toxicol. 2011, 24, 2093-2105.

14. Alexeeff, G.V.; Broadwin, R.; Liaw, J.; Dawson, S.V. Characterization of the LOAEL-to-NOAEL uncertainty factor for mild adverse effects from acute inhalation exposures. Regul. Toxicol. Pharm. 2002, 36, 96-105.

15. GHS - The Globally Harmonized System of classification and labelling of chemicals. Health and Environmental Hazards Classification Criteria for Substances, 2nd ed.; United Nations Economics Commission for Europe, 2007. Available online: http://www.unece.org/trans/danger/ publi/ghs/GHS_presentations/English/health_env_sub_e.pdf (accessed on 11 December 2014).

16. Tjølsen, A.; Hole, K. Animal Models of Analgesia. In The Pharmacology of Pain; Dickenson, A., Besson, J., Eds.; Springer Verlag: Berlin, Germany, 1997; Volume 130, pp. 1-20.

17. Correa, C.R.; Kyke, D.J.; Chakravert, S.; Calixto, J.B. Antinociceptive profile of the pseudopeptide B2 bradykinin and receptor antagonist NPC 18688 in mice. Br. J. Pharmacol. 1996, 117, 552-558. 
18. Ribeiro, R.A.; Vale, M.L.; Thomazzi, S.M.; Paschoalato, A.B.; Poole, S.; Ferreira, S.H.; Cunha, F.Q. Involvement of resident macrophages and mast cells in the writhing nociceptive response induced by zymosan and acetic acid in mice. Eur. J. Pharmacol. 2000, 387, 111-118.

19. Ugwah-Oguejiofor, C.J.; Abubakar, K.; Ugwah, M.O.; Njan, A.A. Evaluation of the antinociceptive and anti-inflammatory effect of Caralluma dalzielii. J. Ethnopharmacol. 2013, 150, 967-972.

20. Khalfoun, B.; Thibault, F.; Watier, H.; Bardos, P.; Lebranchu, Y. Docosahexaenoic and eicosapentaenoic acids inhibit in vitro human endothelial cell production interleukin-6. Adv. Exp. Med. Biol. 1997, 400, 589-597.

21. Calder, P.C. Mechanism of action of (n-3) fatty acids. J. Nutr. 2012, 142, 592S-599S.

22. Zakaria, Z.A.; Ghani, Z.D.F.A.; Nor, R.N.S.R.M.; Gopalan, H.K.; Sulaiman, M.R.; Jais, A.M.M.; Somchit, M.N.; Kader, A.A.; Ripin, J. Antinociceptive, anti-inflammatory, and antipyretic properties of an aqueous extract of Dicranopteris linearis leaves in experimental animal models. J. Nat. Med. 2008, 62, 179-187.

23. Xu, Q.; Wang, Y.; Guo, S.; Shen, Z.; Wang, Y.; Yang, L. Anti-inflammatory and analgesic activity of aqueous extract of Flos populi. J. Ethnopharmacol. 2014, 152, 540-545.

24. Capone, F.; Aloisi, A.M. Refinement of pain evaluation techniques: The formalin test. Ann. Ist. Super. Sanita 2004, 40, 223-229.

25. Amaral, J.F.; Silva, M.I.G.; Aquino Neto, M.R.; Teixeira Neto, P.F.; Moura, B.A.; de Melo, C.T.V.; de Araújo, F.L.O.; de Sousa, D.P.; de Vasconcelos, P.F.; de Vasconcelos, S.M.M.; et al.

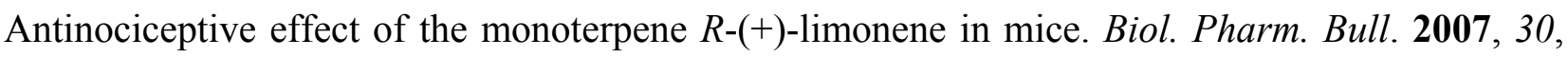
1217-1220.

26. Gonçalves, J.C.R.; Oliveira, F.S.; Benedito, R.B.; Sousa, D.P.; Almeida, R.N.; Araújo, D.A.M.A.D. Antinociceptive activity of (-)-carvone: Evidence of association with decreased peripheral nerve excitability. Biol. Pharm. Bull. 2008, 31, 1017-1020.

27. Kanna, N.; Bathia, J. Antinociception action of Ocimum sanctum (Tulsi) in mice: Possible mechanisms involved. J. Ethnopharmacol. 2003, 88, 293-296.

28. Oliveira, F.S.; Sousa, D.P.; Almeida, R.N. Antinociceptive effect of hydroxydihydrocarvone. Biol. Pharm. Bull. 2008, 31, 588-591.

29. Wang, Y.; Chen, P.; Tang, C.; Wang, Y.; Li, Y.; Zhang, H. Antinociceptive and anti-inflammatory activities of extract and two isolated flavonoids of Carthamus tinctorius L. J. Ethnopharmacol. 2014, 151, 944-950.

30. Anand, R.; Kaithwas, G. Anti-inflammatory potential of alpha-linolenic acid mediated through selective COX inhibition: Computational and experimental data. Inflammation 2014, 37, 1297-1306.

31. Jäger, A.K.; Petersen, K.N.; Thomasen, G.; Christensen, S.B. Isolation of linolenic and $\alpha$-linolenic acids as COX-1 and -2 inhibitors in Rose Hip. Phytother. Res. 2008, 22, 982-984.

32. Cunha, T.M.; Roman-Campos, D.; Lotufo, C.M.; Duarte, H.L.; Souza, G.R.; Verri, W.A., Jr.; Funez, M.I.; Dias, Q.M.; Schivo, I.R.; Domingues, A.C; et al. Morphine peripheral analgesia depends on activation of the PI3K $\gamma / \mathrm{AKT} / \mathrm{nNos} / \mathrm{NO} / \mathrm{Katp}$ signaling pathway. Proc. Natl. Acad. Sci. USA 2010, 107, 4442-4447.

33. Khan, G.R.; Scheinmann, F. Some recent advances in physical methods for analysis and characterization of polyunsaturated fatty acids. Prog. Chem. Fats Lipids 1978, 15, 343-367. 
34. Christie, W.W. Preparation of ester derivatives of fatty acids for chromatographic analysis. In Advances in Lipid Methodology; Christie, W.W., Ed.; Oil Press: Dundee, UK, 1993; pp. 69-111.

35. Miller, L.C.; Tainter, M.L. Estimation of the $\mathrm{LD}_{50}$ and its error by means of logarithmic probit graph paper. Proc. Soc. Exp. Biol. Med. 1994, 57, 261-264.

36. OECD. Guidance Document on Acute Oral Toxicity; Environmental Health and Safety Monograph Series on Testing and Assessment No 24; Environment Directorate OECD: Paris, France, 2000.

37. OECD. Repeated Dose 28-Day Oral Toxicity Study in Rodents; Environment Health and Safety Monograph Series on Testing and Assessment No. 407; Environment Directorate OECD: Paris, France, 1995.

38. Koster, R.; Anderson, M.; de Beer, E.J. Acetic acid for analgesic screening. Fed. Proc. 1959, 18, 412-418.

39. MacDonald, A.D.; Woolfe, G.; Bergel, F.; Morrison, A.L.; Rinderknecht, H. Analgesic action of pethidine derivatives and related compounds. Br. J. Pharmacol. 1946, 1, 4-14.

40. Hunskaar, S.; Hole, K. The formalin test in mice: Dissociation between inflammatory and non-inflammatory pain. Pain 1987, 30, 103-114.

Sample Availability: Samples of fatty oil and pure compounds are available with the authors.

(C) 2015 by the authors; licensee MDPI, Basel, Switzerland. This article is an open access article distributed under the terms and conditions of the Creative Commons Attribution license (http://creativecommons.org/licenses/by/4.0/). 